The views of Mr. Richard Crossman, who presides over the new Department of Health and Social Welfare, on the future of the Health Service have yet to be heard. He will be considering the opinions of many others besides the doctors. The continuing discussions on the Todd Report on medical education ${ }^{4}$ are also relevant, and the long-awaited report of the Royal Commission on Local Government will complete the picture. But Mr. Crossman can hardly ignore the doctors' strong objections to the Green Paper, and any White Paper that comes after must take a markedly different line. The Representarive Meeting, as reported in the Supplement, stated a number of conditions which it thought should be met in any scheme to unify the administrative structure of the N.H.S. There is no lack of opinions on what should be done and how, and it is to be hoped that discussions will now be able to weld them into an agreed, workable scheme.
Meanwhile doctors everywhere have been quietly and spontaneously bringing about their own changes, and organizing themselves to practise modern medicine. In this they have had the willing assistance of administrators, and each branch of the Service has co-operated with the others. These developments suggest that the barriers of the existirg tripartite administrative structure are not so high that those with a will to do so cannot cross them. The role of administration should be to promote and to support medical progress but not to direct it. Perhaps if this were borne in mind when planning reforms the potential assets of the N.H.S. could yet be realized.

1 The Administrative Structure of the Medical and Related Services in England and Wales, 1968. H.M.S.O., London. Price 3s. 6d. net.

" Brit. med. F., Suppl., 1969, 1, 37. Services Review Commintee, 1962. Social Assay, London. 18s. net. Report of the Royal Commission on Medical Education, 1965-68, 1968. H.M.S.O., London.

\section{Female Homosexuality}

The stigma of homosexuality is apt to be attached to any man who deviates at any time and in any way from the currently held image of masculinity. Lesbianism, or female homosexuality, generating less hostility from society, may produce less pressure on the individual to seek the company of others similarly inclined. In contrast to the promiscuity commonly found among male inverts more than half of the female homosexual experiences reported to A. C. Kinsey and his associates ${ }^{1}$ occurred with only a single partner.

The medical concept of homosexuality as a disease entity may have helped to create a climate of sympathy and understanding for those afflicted but has not contributed materially to our knowledge of causation or treatment. Kinsey and his colleagues $^{2}$ did not regard homosexuality as a pathological entity, but rather as the expression of an inherent capacity for indiscriminate sexual response. They describe sexual behaviour as a continuum ranging from the exclusively homosexual to the exclusively heterosexual without distinct boundaries. A homosexual association may involve two individuals who would appear on very different points of the continuum and engage in behaviour ranging from simple pleasure in the company of the other to a hectic physical relationship.

Freud $^{3}$ regarded homosexuality as a result of the interaction between constitution and experience, and subsequent theorists, whether biologically or psychodynamically inclined, have failed to produce a more convincing aetiological explanation. Male homosexuality has been extensively studied, ${ }^{45}$ but

\footnotetext{
${ }_{1}^{1}$ Kinsey, A. C., Pomeroy, W. B., Martin, C. E., and Gebhard, P. H., Sexual Behaviour in the Human Female, 1953. Philadelphia.

2 Kinsey, A. C., Pomeroy, W. B., and Martin, C. E., Sexual Behaviour in the Human Male, 1948. Philadelphia.

3 Freud, S., Three Essays on the Theory of Sexuality, 1949. London.

- Brit. med. 7., 1965, 2, 1077.

s Bieber, I., et al., Homosexuality: A Psychoanalytic Study, 1965. New York.

- Kenyon, F. E., f. Neurol. Neurosurg. Psychiat., 1968, 13, 487.

' Kenyon, F. E., Brit. F. Psychiat., 1968, 114, 1337.
}

lesbianism, though probably affecting 1 in 40 of the female population, has received scant attention.

The recent studies of F. E. Kenyon ${ }^{6}{ }^{7}$ have made an important contribution to this field through data obtained by an anonymous postal survey of 123 committed female homosexuals who were members of a society devoted to their interests and a control group of heterosexual women belonging to another organized group. That the lesser social stigma and greater opportunity for association between two women is none the less associated with considerable personal distress is suggested by the finding that 1 in 4 lesbians wished to become exclusively heterosexual and 1 in 5 had experienced a "nervous breakdown." But the most striking findings lay in the early life experience of these women, for in contrast to the controls more lesbians had a poor relationship with their mother, who was more likely to have had a mental disturbance or to have died. Poor relationships with the father were also more frequent in this group, and fewer of the lesbians' parents' marriages were regarded as satisfactory and more had ended in separation or divorce. Significantly fewer lesbians remembered their childhood as happy, but boarding-school experience bore little relationship to later sexual adjustment.

Fewer lesbians than controls had received any sexual instruction from their mothers, and family attitudes were commonly less accepting and more rejecting of sex. Among the lesbians $24 \%$ reported a family history of homosexuality, most commonly in a brother, but only $2.4 \%$ of controls did so ; $8 \%$ of lesbians reported early homosexual seduction, and $40 \%$ remembered a particularly traumatic sexual advance by a man as compared to $25 \%$ of the controls. More than half of the lesbians had experienced heterosexual intercourse but were more likely than the controls to have found it unsatisfactory. The mean age of first awareness of homosexual feelings was 16 years and the mean age for first physical experience was 21 years. In contrast with the control group fewer lesbians regarded themselves as fully feminine, many more had been members of uniformed women's services, more had a university education, and fewer had a stable work record. 
Anomalies of early relationships with parents and repressive family attitudes towards sexuality are among the most consistent findings in studies of homosexuality in either sex. Despite our inadequate knowledge of the development of sexual orientation it is possible to recognize circumstances specially apt to result in anomalous sexual development. Children reared in families which are incomplete, disturbed by distortions in personal relationships, or whose sexual attitudes are markedly clouded by repression or ignorance appear to be particularly vulnerable. Specific difficulties in relating to other people, lack of opportunity for satisfactory social contact with the opposite sex, or undue exposure to erotically stimulating contact with members of the same sex, such as may occur in single sex institutions or organizations, may result in the stirring of homosexual feelings in the adolescent. If this occurs in an individual factually or emotionally unprepared for adult sexuality it may form the basis for a lifelong pattern of sexual function. It is particularly important to stress that these homosexual feelings do not inevitably imply homosexuality. However, homosexual contacts are often as effective as heterosexual in the male and more effective in the female in bringing the individual to orgasm, so that once physical behaviour is established it becomes extremely difficult to displace.

\section{Is Quinidine Outdated ?}

Quinidine, the dextro-isomer of quinine, is one of the natural alkaloids found in cinchona bark. It has been recognized as an agent for the treatment of arrhythmias for over 100 years. While quinidine shares with quinine antimalarial, antipyretic, and oxytocic actions, and both are skeletal muscle depressants, it was for its cardiac actions that it came to occupy an almost unique position in therapeutics for almost half a century.

Quinidine acts on cardiac muscle to depress excitability, conduction velocity, and contractility. It also lowers peripheral vascular resistance. Quinidine sulphate is the most commonly used short-acting preparation given by mouth. Two long-acting preparations, quinidine polygalacturonate and quinidine bisulphate, have recently been marketed embedded in a porous insoluble plastic tablet for slow release. Quinidine bisulphate and the more soluble quinidine gluconate have been used in the past for intravenous injection, but since syncope can occur this route should not be used.

Before the introduction of direct-current (D.C.) countershock therapy, quinidine was used in large doses to convert atrial fibrillation to sinus rhythm, and in smaller doses to prevent recurrences of atrial fibrillation. It was also given for the prevention and treatment of atrial flutter after digitalization and for the prevention and treatment of supraventricular tachycardias, ventricular tachycardia, and extrasystoles. Lesser-known uses of quinidine are in the treatment of intractable hiccup and as an aid to the diagnosis of the Wolff-Parkinson-White syndrome by depressing the aberrant conduction pathway.

Quinidine is a cumulative drug, and large doses give rise to cinchonism, characterized by tinnitus, headache, nausea, abdominal pain, skin rashes, disturbed vision, and amaurosis. The effects of large doses of quinidine on the heart include extrasystoles, atrioventricular and intraventricular block, ventricular tachycardia and fibrillation, and cardiac asystole. The incidence of death due to the use of quinidine in the treatment of chronic atrial arrhythmias has been quoted as being between $3 \%$ and $4 \%$. Systemic embolism and toxic effects on the myocardium and the central nervous system have been blamed for sudden deaths during quinidine therapy. $^{1{ }^{2}}$ A. Selzer and H. W. Wray, ${ }^{1}$ however, have pointed out that "quinidine syncope," which in their experience was a common event, was usually due to paroxysmal ventricular fibrillation. It may occur after modest doses of quinidine and in the presence of "relatively low quinidine blood levels." This suggests that ventricular fibrillation is commonly due to myocardial sensitivity to quinidine and not to the toxic effect of high blood levels of the drug as implied by $M$. Sokolow and D. B. Perloff. ${ }^{3}$ These findings, subsequently confirmed by others, reinforce the importance of a test dose of quinidine and of never initiating quinidine therapy without there being adequate monitoring and resuscitative equipment close at hand. Idiosyncrasy to small doses of quinidine may also take the form of nausea, vomiting, and diarrhoea ; tinnitus, confusion, headache, and visual disturbances ; skin rashes, angioneurotic oedema, cramps ; thrombocytopenic purpura (which is rare); asthma, respiratory depression or arrest, and hypotension.

The introduction of D.C. shock therapy for the correction of cardiac arrhythmias has relegated quinidine to the status of a prophylactic antiarrhythmic agent. Until facilities for D.C. shock therapy become more generally available, however, quinidine will continue to have its supporters. ${ }^{4}$ Some workers have recently advocated the combined use of quinidine and propranolol in the management of recurrent or resistant arrhythmias. ${ }^{5}{ }^{6}$ B. Lown ${ }^{7}$ regards quinidine as an important drug in the prevention of recurrences of atrial fibrillation. In his view intolerance to this drug is a relative contraindication to the use of countershock therapy in atrial fibrillation. S. Oram and J. P. H. Davies ${ }^{8}$ have shown quinidine to have no effect on the incidence of recurrence of atrial fibrillation following restoration of sinus rhythm by D.C. shock. These authors suggested that D.C. shock might even sensitize the myocardium to the effects of quinidine, rendering the patient liable to "late" cardiac arrest. This suggestion was supported by $\mathrm{O}$. Brenner and his colleagues. ${ }^{9}$

1 Selzer, A., and Wray, H. W., Circulation, 1964, 30, 17.

2 Thomson, G. W., Circulation, 1956, 14, 757.

Sokolow, M., and Perloff, D. B., Progr. cardiovasc. Dis., 1960-61, 3, 316.

Cookson, H., Lancet, 1964, 2, 1240

5 Stern, S., Amer. Heart f., 1967, 74, 170

Reynolds, E. W., and VanderArk, C. R., Circulation, 1967, 36, Suppl. No. 2, 221.

7 Lown, B., Brit. Heart f., 1967, 29, 469.

8 Oram, S., and Davies, J. P. H., Lancet, 1964, 1, 1294.

Brenner, O., Davison, P. H., and Evans, D. W., Lancet, 1964, 2 1184.

10 Hall, J. I., and Wood, D. R., Brit. Heart F., 1968, 30, 84

11 Spracklen, F. H. N., Kimerling, J. J., Besterman, E. M. M., and Litchfield, J. W., Brit. med. f., 1968, 1, 89.

12 Jewitt, D. E., Kishon, Y., and Thomas, M., Lancet, 1968, 1, 266.

13 Conn, R. D., New Engl. f. Med., 1965, 272, 277.

14 Bacaner, M. B., Amer. F. Cardiol., 1968, 21, 530.

15 Rosen, M., Lisak, R., and Rubin,'I. L., Amer. F. Cardiol., 1967, 20 674.

16 Moe, G. K., and Abildskov, J. A., in The Pharmacological Basis of Therapeutics, 1965, 3rd ed., p. 711, edited by L. S. Goodman and A. Gilman. New York.

17 Linko, E., Ruosteenoja, R., and Siitonen, L., Amer. Heart f., 1968, 75, 139 .

18 Balcon, R., Jewitt, D. E., Davies, J. P. H., and Oram, S., Lancet, 1966, 2,917.

19 Besterman, E. M. M., and Friedlander, D. H., Postgrad. med. 7 . $1965,41,526$

20 Tsolakas, T. C., Davies, J. P. H., and Oram, S., Lancet, 1964, 2 , 1064 .

21 Bay, G., Lund-Larsen, P., Lorentsen, E., and Sivertssen, E., Brit. med. ̈., 1967, 1, 141 